\title{
PERCEPÇÃO DE CONSUMIDORES DE FEIRAS ORGÂNICAS DA CIDADE DE SÃO PAULO (SP)
}

\author{
Kleber Spíndola Gonçalves* \\ Ana Paula Branco do Nascimento** \\ Simone Aquino**** \\ Andreza Portella Ribeiro***** \\ Leonardo Vils ${ }^{* * * * * *}$ \\ Mauricio Lamano Ferreira*******
}

RESUMO: A agricultura convencional emprega agrotóxicos e o uso excessivo destes produtos causa danos para a saúde e o meio ambiente. A agricultura orgânica diferentemente da agricultura convencional não faz uso de produtos químicos tóxicos, fitorreguladores (hormônios vegetais sintéticos) e sementes geneticamente modificadas, oferecendo alimentos para um novo consumidor, interessado em uma produção baseada na sustentabilidade, sem emprego de agrotóxicos, mais natural e ainda com valores sociais e agregados à origem e segurança dos alimentos, visto que o sistema da agricultura orgânica se inicia do preparo do solo até a fase de comercialização. Verifica-se um mercado diferenciado em crescimento e com grande perspectiva de crescimento e, devido a isso, objetivou-se analisar a percepção de consumidores de produtos orgânicos sobre quais as razões da aquisição em feiras orgânicas. Para isto, foi realizada uma pesquisa quantitativa por meio de entrevista, com aplicação de um roteiro semiestruturado em escala Likert. A maioria dos consumidores escolhem produtos orgânicos pelos benefícios à saúde, mas 90,5\% percebem que consumir alimentos orgânicos traz benefícios para o meio ambiente. Os consumidores têm preferência por feiras livres, quando comparados aos alimentos orgânicos oferecidos em supermercados, tanto por conta da qualidade quanto

\footnotetext{
* Mestre em Administração com ênfase em Gestão Ambiental e Sustentabilidade pela Universidade Nove de Julho (UNINOVE), Brasil.

${ }^{* *}$ Doutora em Ecologia, Docente Mestrado Profissional em Gestão Ambiental e Sustentabilidade pela Universidade Nove de Julho (UNINOVE), Brasil. E-mail: apbnasci@yahoo.com.br

***: Doutora em Ciências e Docente do Programa de Mestrado Profissional em Gestão Ambiental e Sustentabilidade pela Universidade Nove de Julho (UNINOVE), Brasil.

***** Doutora em Ciências com ênfase em Química Ambiental e Docente do Mestrado Acadêmico em Cidades Inteligentes e Sustentáveis pela Universidade Nove de Julho (CIS-UNINOVE), Brasil.

****** Doutor em Administração, Docente do Mestrado Profissional em Gestão Ambiental e Sustentabilidade pela Universidade Nove de Julho (GEAS - UNINOVE), Brasil.

***:*** Doutor em Ciências, Docente do Mestrado Acadêmico em Cidades Inteligentes e Sustentáveis pela Universidade Nove de Julho (CIS-UNINOVE), Brasil.
} 
do preço. Por meio de análise de variância (ANOVA) foi verificada a existência de diferenças de percepção por gênero, faixa etária e escolaridade. Compreender a percepção de consumidores neste mercado em ascensão contribui também para o marketing verde, na cadeia de alimentos orgânicos.

PALAVRAS-CHAVE: Agricultura; Orgânicos; Percepção Ambiental; Sustentabilidade.

\section{CONSUMER PERCEPTION ON ORGANIC PRODUCT FAIRS IN SÃO PAULO, BRAZIL}

ABSTRACT: Traditional agriculture employs agrotoxics. Their excess causes damages to health and to the environment. Organic agriculture is contrastingly different and does not use toxic chemical products, phyto-regulators (synthetic vegetal hormones) and genetically modified seeds. It provides food for a new type of consumer who is interested in a type of produce based on sustainability, without agrotoxics, natural, coupled to social values and aggregated to food's origin and safety. In fact, the organic agricultural system starts from soil preparation and ends in the products' commercialization. One may perceive a type of market different in growth and with great growth perspectives. Current assay analyzes the perception of consumers of organic products and the reasons for their acquisition of products on the organic market. A quantitative research was undertaken by an interview, applying a semi-structure script with the Likert scale. Most consumers select organic products for health and $95 \%$ perceive that the consumption of organic products is also beneficial to the environment. Consumers prefer country fairs to those offered at supermarkets due to quality and price. Analysis of variance (ANOVA) verified differences in perceptions by gender, age bracket and schooling. Understanding the perception of consumers in this growing market also contributes towards a green marketing within the organic food chain.

KEY WORDS: Agriculture; Organic products; Environmental perception; Sustainability.

\section{INTRODUÇÃO}

A população tem buscado melhor qualidade de vida nas cidades e dentre os desafios para melhorar a saúde e bem-estar da população estão a prática de atividades físicas, a busca por uma alimentação mais saudável (CHEN, 2009), e o contato 
com espaços verdes (LEE; MAHESWARAN, 2010; FRANÇA et al., 2016). A produção e escolha de alimentos trazem implicações tanto para a saúde humana como para o meio ambiente, ou seja, podendo refletir tanto a atitude de consumidores em relação ao meio ambiente quanto sua preocupação com a saúde (NANDI et al., 2016).

Desde a Revolução Agrícola a alimentação vem se tornando mais fácil para os seres humanos (HARARI, 2015). Entre 10 e 15 mil anos atrás, o processo de domesticação de algumas espécies de plantas e animais, denominada Revolução Agrícola, permitiu que povos, antes nômades, se fixassem permanentemente em um território (TILIO, 2010). O grande aumento de produtividade decorrente da domesticação proporcionou uma maior segurança alimentar que, por sua vez, deu impulso a um grande crescimento populacional (HARARI, 2015). Desde então, o crescimento da população tem estimulado a adoção de novas estratégias empregadas na agricultura tradicional intensificando, por exemplo, o uso de pesticidas que, potencialmente, causam danos ambientais e à saúde

Nas últimas décadas, o uso indiscriminado de agrotóxicos na produção de alimentos vem causando preocupação em diversas partes do mundo e esse modelo tem sido muito criticado, e cresce à medida que estudos comprovam que o uso excessivo de agrotóxicos causam danos a saúde e ao meio ambiente (ARCHANJO et al., 2001; SILVA et al., 2005; DIAS et al., 2016).

A busca por uma forma equilibrada de produção, e que atenda aos interesses de todos, tem aumentado as discussões de governos, ONG's, cientistas e comunidade. $\mathrm{O}$ modelo de produção orgânica é considerado uma alternativa de produção limpa capaz de contribuir para a redução do impacto ambiental e substituir o modelo tradicional de produção agrícola (CASEMIRO; TREVIZAN, 2009). Um exemplo é o guia alimentar da população brasileira que na última versão do ano de 2014 menciona o consumo de alimentos orgânicos para garantir a segurança alimentar da população.

A agricultura orgânica é um sistema de produção que em sua essência visa práticas sustentáveis de produção, não fazendo uso de qualquer tipo de fertilizante ou defensivos sintéticos (PENTEADO, 2003). Como alternativa, sugere-se o uso de fertilizantes de origem animal e inseticidas naturais a base de resíduos animal e vegetal (PAULUS et al., 2000). 
A produção orgânica, conceitualmente um conjunto de princípios e técnicas alternativas à agricultura convencional (CAMPANHOLA; VALARINI, 2001), é abrangente, compreendendo a agricultura natural, biodinâmica, biológica e permacultura. Além de técnicas específicas adotadas no cultivo orgânico, a agricultura orgânica segue o princípio da sustentabilidade, da minimização do uso de energia não renovável e da maximização do recurso social (VILCKAS; NANTES, 2011).

Para que um alimento receba a denominação de orgânico ele obrigatoriamente deve ser rotulado como tal e submetido a um sistema de certificação que leva em conta os princípios estabelecidos pela legislação brasileira, segundo o Decreto $\mathrm{n}^{\circ} 6.323$ de 2007 que regulamentou a Lei n 10.831 , de 23 de dezembro de 2003, e que dispõe sobre a agricultura orgânica. A certificação confere ao alimento orgânico o status de produto ecológico, ou seja, a sua cadeia produtiva envolve operações sustentáveis, garantindo que se trata de um produto que não causa danos ao meio ambiente ou à saúde (ABREU et al., 2009; BRASIL, 2007; BRASIL, 2003).

A agricultura orgânica está atrelada ao chamado marketing verde que, segundo Lopes e Pacagnan (2014), surge como uma ferramenta estratégica que visa equilibrar o consumo da sociedade com o mínimo de impacto ao meio ambiente, criando produtos ecologicamente corretos desde a sua produção até o seu descarte para atender a uma demanda crescente de clientes ambientalmente conscientes.

Para Gonzaga (2005), o termo marketing verde refere-se aos instrumentos mercadológicos utilizados para explorar os benefícios ambientais proporcionados por um produto. Assim, os mais valorizados, de acordo com o autor, são aqueles que contribuem para a sustentabilidade. Como há predominância do padrão de consumo sobre o padrão de produção, os hábitos de consumo e estilo de vida dos consumidores moldam os padrões produtivos. Atender as expectativas e necessidades dos consumidores, tanto as de utilidade e conveniência (individuais) quanto as intangíveis e não-comerciais, reforça o marketing de diferenciação ambiental como uma atitude de responsabilidade social.

O Ministério de Agricultura, Pecuária e Abastecimento (MAPA) divulgou que atualmente existe uma procura em franco crescimento por produtos orgânicos. O mercado de produtores orgânicos cadastrados cresceu em 2014 51,7\% (MAPA, 2015). Portanto, a fim de contribuir para a compreensão das razões de consumido- 
res na busca de produtos orgânicos, o presente estudo tem a seguinte questão de pesquisa: Qual o perfil dos consumidores e suas percepções sobre a sustentabilidade atrelada ao mercado de produtos orgânicos?

\section{MATERIAL E MÉTODOS}

\subsection{LOCAL DE FEIRAS ORGÂNICAS}

Foram selecionadas para o estudo quatro feiras orgânicas localizadas no Parque Água Branca, na cidade de São Paulo (SP). O Parque foi criado em 02 de junho de 1929 pelo então secretário de Agricultura, Fernando Costa. Em 1950 foi oficialmente batizado de Parque Dr. Fernando Costa em homenagem ao seu idealizador e está localizado na Zona Oeste do município (Figura 1). É aberto ao público diariamente no período das 6 às $20 \mathrm{~h}$.

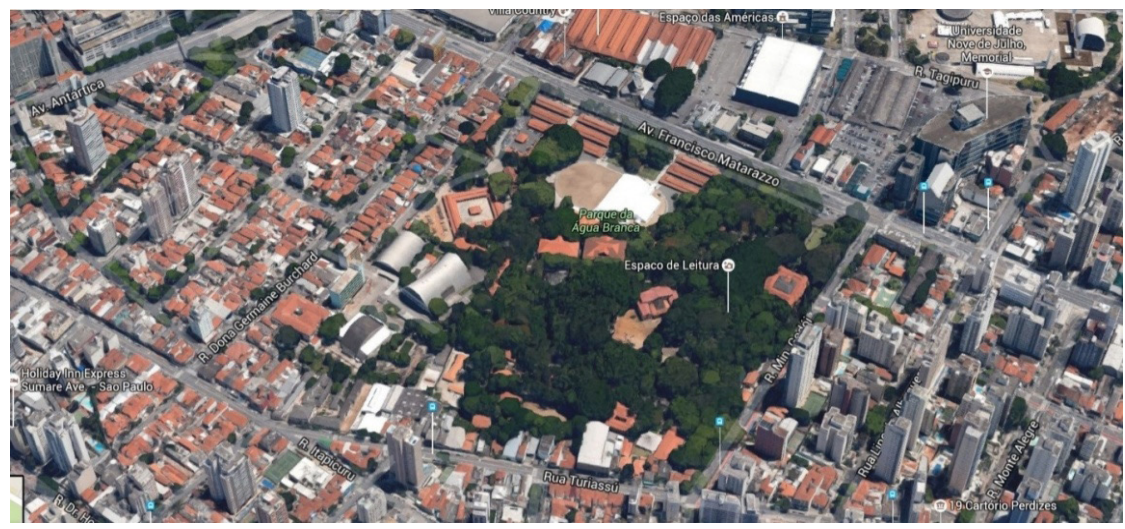

Figura 1. Localização do Parque da Água Branca no município de São Paulo (SP). Fonte: Google Earth, 2017.

As feiras orgânicas ocorrem em um galpão coberto com aproximadamente $800 \mathrm{~m}^{2}$ e ocorrem três dias por semana: terças-feiras das 07 às $12 \mathrm{~h}$; terças-feiras das 16 às 19h30; aos sábados (primeira feira orgânica do Brasil) e domingos das 07 às 12h. As feiras estão sob a administração da Associação de Agricultura Orgânica (AAO) e são consideradas distintas entre si, pois possuem em sua composição agricultores 
diferentes em cada dia ou período.

A primeira feira foi inaugurada em 23 de fevereiro de 1991 com o total de 12 produtores orgânicos. A AAO foi a primeira organização não governamental (ONG) a criar regras de cultivo orgânico centradas na realidade local da população e estipulando critérios básicos para os agricultores se credenciarem na Associação (LAMANO-FERREIRA et al., 2017). Atualmente a feira possui 45 produtores cadastrados e autorizados a realizarem a venda de seus produtos em um dos dias em que a feira ocorre. São comercializados produtos in natura ou industrializados, sendo parte produzido pelos próprios produtores e parte por terceiros.

\subsection{INSTRUMENTO DE PESQUISA}

Os dados foram coletados por meio de roteiro estruturado para 360 respondentes, em duas partes: perfil socioambiental dos respondentes e percepção sobre produtos orgânicos. Na primeira seção (A), foi caracterizado o perfil dos respondentes e, na seção B, buscou-se conhecer os motivos da escolha dos consumidores. Sete assertivas com cinco opções de resposta em escala Likert (discordo muito, discordo pouco, não concordo, nem discordo, concordo pouco e concordo muito) foram lidas para entrevistados para a escolha de apenas uma das opções de cada assertiva (HAIR Jr et al., 2005).

Quadro 1. Fatores do perfil sociambiental do consumidor, percepção sobre produtos orgânicos e percepção sobre a feira orgânica

(Continua)

\begin{tabular}{|l|l|}
\hline Seção A: Perfil socioambiental & $\begin{array}{l}\text { Seção B: Percepção sobre produtos orgâ- } \\
\text { nicos }\end{array}$ \\
\hline $\begin{array}{l}\text { Traçar o perfil socioambiental dos consumi- } \\
\text { dores de alimentos orgânicos das feiras }\end{array}$ & $\begin{array}{l}\text { Investigar motivos relacionados à escolha } \\
\text { de produtos orgânicos }\end{array}$ \\
\hline 1. Sexo; & $\begin{array}{l}\text { 11. Gosto de consumir produtos orgânicos } \\
\text { porque trazem benefícios para a saúde }\end{array}$ \\
\hline 2. Idade; & $\begin{array}{l}\text { 12. Gosto de consumir produtos orgânicos } \\
\text { porque trazem benefícios para o meio am- } \\
\text { biente }\end{array}$ \\
\hline 3. Escolaridade; & $\begin{array}{l}\text { 13. Me disponho a pagar mais caro por produ- } \\
\text { to orgânico }\end{array}$ \\
\hline
\end{tabular}


(Conclusão)

\begin{tabular}{|l|l|}
\hline Seção A: Perfil socioambiental & $\begin{array}{l}\text { Seção B: Percepção sobre produtos orgâ- } \\
\text { nicos }\end{array}$ \\
\hline 4. Número de filhos; & $\begin{array}{l}\text { 14. Os alimentos orgânicos são mais saudáveis, } \\
\text { pois são livres de agrotóxicos, hormônios e } \\
\text { outros produtos químicos }\end{array}$ \\
\hline 5. Bairro da residência; & $\begin{array}{l}\text { 15. Eu compro alimentos orgânicos no super- } \\
\text { mercado }\end{array}$ \\
\hline $\begin{array}{l}\text { 6. Número de vezes que frequenta a feira por } \\
\text { mês; }\end{array}$ & $\begin{array}{l}\text { 16. No supermercado encontro produtos orgâ- } \\
\text { nicos com mais qualidade do que na feira }\end{array}$ \\
\hline $\begin{array}{l}\text { 7. Como se desloca até a feira; } \\
\text { 17. Na feira compro produtos orgânicos mais } \\
\text { barato que no supermercado }\end{array}$ \\
\hline $\begin{array}{l}\text { 8. Com quem costuma frequentar a feira (sozi- } \\
\text { nho ou acompanhado?). }\end{array}$ & \\
\hline $\begin{array}{l}\text { 9. Há quantos anos você consome produtos } \\
\text { orgânicos? }\end{array}$ & \\
\hline $\begin{array}{l}\text { 10. Quando você começou a consumir produtos } \\
\text { orgânicos e porque? }\end{array}$ & \\
\hline
\end{tabular}

Fonte: Elaborado pelos autores.

\subsection{ANÁLISE QUANTITATIVA}

Os dados foram compilados no software Microsoft Office Excel versão 2010 e analisados por meio do software Statistical Package for the Social Sciences (SPSS). Posteriormente analisou-se o grau de concordância dos respondentes para cada afirmação, a frequência de cada variável, cruzamento das variáveis e ao agrupamento de variáveis. Por meio de análise de variância (ANOVA) foi verificada a existência de diferenças de percepção por gênero, faixa etária e escolaridade. Adotou-se o nível de significância de 0,05 ( $\mathrm{p}<0,05$ ), padrão das ciências sociais aplicadas (Hair et al., 2005). 


\section{RESULTADOS E DISCUSSÃO}

\subsection{PERFIL DA AMOSTRA}

Do total das 360 entrevistas com frequentadores da feira, $68,1 \%$ foram do sexo feminino. A faixa etária predominante está entre 31 e 60 anos correspondendo a $66,4 \%$ do total. Os entrevistados, em sua maioria $(65,8 \%)$, frequentam a feira semanalmente, e, sozinhos, 46,4\%, ou acompanhados, 46,7\%. Dos entrevistados, $77,5 \%$, declararam ter pelo menos graduação completa, o que levanta a hipótese de que indivíduos com maior formação escolar podem ter atitudes mais favoráveis sobre produtos orgânicos. Mais da metade da amostra $(58,1 \%)$ declarou consumir produtos orgânicos a mais de 4 anos. Além disso, o deslocamento até a feira não representa um fator impeditivo ao consumo de produtos orgânicos, visto que 55,6\% dos entrevistados se deslocam de carro, $23,9 \%$ a pé e $20,5 \%$ usam outros meios.

Tabela 1. Perfil dos consumidores de produtos orgânicos entrevistados em feiras na cidade de São Paulo

(Continua)

\begin{tabular}{|c|c|c|c|c|c|}
\hline \multirow{3}{*}{ Variável } & \multirow{3}{*}{ Item } & \multirow{3}{*}{$\begin{array}{l}\text { (n) } \\
360\end{array}$} & \multirow{3}{*}{$\begin{array}{l}(\%) \\
100\end{array}$} & \multicolumn{2}{|c|}{ Gênero } \\
\hline & & & & Feminino & Masculino \\
\hline & & & & $\begin{array}{c}(n= \\
245 / 68,1 \%)\end{array}$ & $\begin{array}{c}(\mathrm{n}= \\
115 / 31,9 \%)\end{array}$ \\
\hline \multirow{7}{*}{ Idade } & De 20 a 30 anos & 31 & 8,6 & 4,4 & 4,2 \\
\hline & De 31 a 40 anos & 80 & 22,2 & 13,9 & 8,3 \\
\hline & De 41 a 50 anos & 69 & 19,2 & 13,6 & 5,6 \\
\hline & De 51 a 60 anos & 90 & 25 & 17,8 & 7,2 \\
\hline & De 61 a 70 anos & 60 & 16,7 & 12,3 & 4,4 \\
\hline & De 71 a 80 anos & 28 & 7,7 & 5,8 & 1,9 \\
\hline & Acima de 80 anos & 2 & 0,6 & 0,3 & 0,3 \\
\hline \multirow{2}{*}{ Escolaridade } & Fundamental & 81 & 22,5 & 70,4 & 29,6 \\
\hline & Graduação & 279 & 77,5 & 67,4 & 32,6 \\
\hline \multirow{2}{*}{ Tempo que consome } & Até 4 anos & 151 & 41,9 & 64,2 & 35,8 \\
\hline & Acima de 4 anos & 209 & 58,1 & 70,8 & 29,2 \\
\hline
\end{tabular}


(Conclusão)

\begin{tabular}{|c|c|c|c|c|c|}
\hline \multirow{3}{*}{ Variável } & \multirow{3}{*}{ Item } & \multirow{3}{*}{$\begin{array}{l}\text { (n) } \\
360\end{array}$} & \multirow{3}{*}{$\begin{array}{l}(\%) \\
100\end{array}$} & \multicolumn{2}{|c|}{ Gênero } \\
\hline & & & & Feminino & Masculino \\
\hline & & & & $\begin{array}{c}(n= \\
245 / 68,1 \%)\end{array}$ & $\begin{array}{c}(\mathrm{n}= \\
115 / 31,9 \%)\end{array}$ \\
\hline \multirow{3}{*}{$\begin{array}{c}\text { Como se desloca até } \\
\text { a feira }\end{array}$} & A pé & 86 & 23,9 & 69,8 & 30,2 \\
\hline & De carro & 200 & 55,6 & 64,5 & 35,5 \\
\hline & Outros & 74 & 20,5 & 75,7 & 24,3 \\
\hline \multirow{2}{*}{$\begin{array}{l}\text { Motivo que o levou a } \\
\text { consumir alimentos } \\
\text { orgânicos }\end{array}$} & Saúde & 227 & 63,1 & 68,3 & 31,7 \\
\hline & Outros & 133 & 36,9 & 67,7 & 32,3 \\
\hline \multirow{2}{*}{ Filhos } & Sim & 247 & 68,6 & 69,2 & 30,8 \\
\hline & Não & 113 & 31,4 & 65,5 & 34,5 \\
\hline \multirow{4}{*}{$\begin{array}{l}\text { Vezes que frequenta } \\
\text { a feira }\end{array}$} & Uma vez por mês & 28 & 7,8 & 50 & 50 \\
\hline & Duas vezes por mês & 76 & 21,1 & 69,7 & 30,3 \\
\hline & Quatro vezes por mês & 237 & 65,8 & 69,2 & 30,8 \\
\hline & $\begin{array}{l}\text { Mais de quatro vezes por } \\
\text { mês }\end{array}$ & 19 & 5,3 & 73,7 & 26,3 \\
\hline \multirow{3}{*}{$\begin{array}{c}\text { Com quem frequenta } \\
\text { a feira }\end{array}$} & Sozinho & 167 & 46,4 & 73 & 27 \\
\hline & Acompanhado & 168 & 46,7 & 63,7 & 36,3 \\
\hline & Sozinho/Acompanhado & 25 & 6,9 & 64 & 36 \\
\hline \multirow{2}{*}{$\begin{array}{l}\text { Frequenta outras } \\
\text { feiras }\end{array}$} & Não & 305 & 84,7 & 67,9 & 32,1 \\
\hline & Sim & 55 & 15,3 & 69 & 31 \\
\hline
\end{tabular}

Fonte: Elaborado pelos autores.

A motivação para o consumo de produtos orgânicos está relacionada à saúde para 63,1\% dos respondentes, outras motivações como a não presença de agrotóxicos, influência de outras pessoas ou a consciência ecológica somam 36,9\%. Conforme a pesquisa de Ravelli, Moraes e Lima-Filho (2014), os respondentes declararam possuir um estilo de vida mais saudável e alegaram que a escolha pela compra dos produtos orgânicos está relacionada com a qualidade e os benefícios à saúde.

Estudo realizado por Chen (2009) corrobora com a crescente tendência da procura pela população por alimentos de melhor qualidade e não somente por serem livres de agrotóxicos, mas simplesmente porque gostam de experimentar produtos novos e diferentes (DHIVYA; RANGASWAMY, 2016). Portanto, as mudanças 
que ocorreram no setor de produção de alimentos fizeram (e fazem) com que os consumidores se tornem mais preocupados com fatores relacionados com a alimentação e meio ambiente (BARBOSA et al., 2011).

\subsection{PERCEPÇÃO E ATITUDE SOBRE CONSUMO DE PRODUTOS ORGÂNICOS}

Das sete assertivas estudadas, quatro delas (assertivas, 1, 2, 3 e 4), a maioria concorda totalmente. Dentre elas pode-se citar a assertiva 1: "Gosto de consumir alimentos orgânicos porque trazem benefícios para a saúde", onde foi constatado que $95,8 \%$ concordam muito com a respectiva afirmação, e na assertiva 2 "Gosto de consumir alimentos orgânicos porque trazem benefícios para o meio ambiente" foi constatado que o total de $90,5 \%$ dos entrevistados disseram que concordam muito com a afirmação (Tabela 2).

Tabela 2. Grau de concordância das assertivas pelos consumidores entrevistados (20152016)

(Continua)

\begin{tabular}{|c|c|c|c|c|c|}
\hline \multirow{2}{*}{ Variável } & \multirow{2}{*}{ Item } & \multirow{2}{*}{$\begin{array}{l}\text { Frequência } \\
n=360\end{array}$} & \multirow{2}{*}{$\begin{array}{c}\text { Porcentagem } \\
\text { Total \% }\end{array}$} & \multicolumn{2}{|c|}{ Gênero } \\
\hline & & & & $\begin{array}{c}\text { Feminino } \\
\%\end{array}$ & $\begin{array}{l}\text { Mascu- } \\
\text { lino \% }\end{array}$ \\
\hline \multirow{5}{*}{$\begin{array}{l}\text { 1. Gosto de consumir } \\
\text { alimentos orgânicos } \\
\text { porque trazem benefícios } \\
\text { para a saúde. }\end{array}$} & Discordo muito & 0 & 0 & 0 & 0 \\
\hline & Discordo pouco & 2 & 0,6 & 0 & 0,6 \\
\hline & $\begin{array}{l}\text { Não concordo } \\
\text { nem discordo }\end{array}$ & 1 & 0,3 & 0 & 0,3 \\
\hline & Concordo pouco & 12 & 3,3 & 1,1 & 2,2 \\
\hline & Concordo muito & 345 & 95,8 & 66,9 & 28,9 \\
\hline \multirow{5}{*}{$\begin{array}{l}\text { 2. Gosto de consumir } \\
\text { alimentos orgânicos } \\
\text { porque trazem benefícios } \\
\text { para o meio ambiente. }\end{array}$} & Discordo muito & 0 & 0 & 0 & 0 \\
\hline & Discordo pouco & 2 & 0,6 & 0,6 & 0 \\
\hline & $\begin{array}{l}\text { Não concordo } \\
\text { nem discordo }\end{array}$ & 3 & 0,8 & 0,2 & 0,6 \\
\hline & Concordo pouco & 29 & 8,1 & 3,1 & 5 \\
\hline & Concordo muito & 326 & 90,5 & 64,2 & 26,3 \\
\hline
\end{tabular}


(Conclusão)

\begin{tabular}{|c|c|c|c|c|c|}
\hline \multirow[b]{2}{*}{ Variável } & \multirow[b]{2}{*}{ Item } & \multirow{2}{*}{$\begin{array}{l}\text { Frequência } \\
\mathrm{n}=360\end{array}$} & \multirow{2}{*}{$\begin{array}{c}\text { Porcentagem } \\
\text { Total } \%\end{array}$} & \multicolumn{2}{|c|}{ Gênero } \\
\hline & & & & $\begin{array}{c}\text { Feminino } \\
\%\end{array}$ & $\begin{array}{l}\text { Mascu- } \\
\text { lino \% }\end{array}$ \\
\hline \multirow{5}{*}{$\begin{array}{l}\text { 3. Me disponho a pagar } \\
\text { mais caro por um produ- } \\
\text { to orgânico. }\end{array}$} & Discordo muito & 9 & 2,5 & 1,4 & 1,1 \\
\hline & Discordo pouco & 13 & 3,6 & 2,5 & 1,1 \\
\hline & $\begin{array}{l}\text { Não concordo } \\
\text { nem discordo }\end{array}$ & 21 & 5,8 & 3,1 & 2,7 \\
\hline & Concordo pouco & 107 & 29,8 & 19,4 & 10,4 \\
\hline & Concordo muito & 210 & 58,3 & 41,7 & 16,6 \\
\hline \multirow{5}{*}{$\begin{array}{l}\text { 4. Os alimentos orgâni- } \\
\text { cos são mais saudáveis, } \\
\text { pois são livres de agrotó- } \\
\text { xicos, hormônios e ou- } \\
\text { tros produtos químicos. }\end{array}$} & Discordo muito & 3 & 0,8 & 0,6 & 0,2 \\
\hline & Discordo pouco & 0 & 0 & 0 & 0 \\
\hline & $\begin{array}{l}\text { Não concordo } \\
\text { nem discordo }\end{array}$ & 1 & 0,3 & 0,3 & 0 \\
\hline & Concordo pouco & 12 & 3,3 & 1,4 & 1,9 \\
\hline & Concordo muito & 344 & 95,6 & 65,8 & 29,8 \\
\hline \multirow{5}{*}{$\begin{array}{l}\text { 5. Eu compro alimentos } \\
\text { orgânicos no supermer- } \\
\text { cado. }\end{array}$} & Discordo muito & 88 & 24,4 & 15,8 & 8,6 \\
\hline & Discordo pouco & 42 & 11,7 & 8,1 & 3,6 \\
\hline & $\begin{array}{l}\text { Não concordo } \\
\text { nem discordo }\end{array}$ & 39 & 10,8 & 7,5 & 3,3 \\
\hline & Concordo pouco & 99 & 27,5 & 18,3 & 9,2 \\
\hline & Concordo muito & 92 & 25,6 & 18,3 & 7,3 \\
\hline \multirow{5}{*}{$\begin{array}{l}\text { 6. No supermercado } \\
\text { encontro alimentos orgâ- } \\
\text { nicos com mais qualida- } \\
\text { de do que na feira. }\end{array}$} & Discordo muito & 209 & 58,1 & 40,6 & 17,5 \\
\hline & Discordo pouco & 76 & 21 & 14,4 & 6,6 \\
\hline & $\begin{array}{l}\text { Não concordo } \\
\text { nem discordo }\end{array}$ & 42 & 11,7 & 6,7 & 5 \\
\hline & Concordo pouco & 22 & 6,1 & 4,7 & 1,4 \\
\hline & Concordo muito & 11 & 3,1 & 1,7 & 1,4 \\
\hline \multirow{5}{*}{$\begin{array}{l}\text { 7. Na feira compro } \\
\text { produto orgânico mais } \\
\text { barato do que no super- } \\
\text { mercado }\end{array}$} & Discordo muito & 35 & 9,8 & 7,2 & 2,6 \\
\hline & Discordo pouco & 22 & 6,1 & 3,6 & 2,5 \\
\hline & $\begin{array}{l}\text { Não concordo } \\
\text { nem discordo }\end{array}$ & 88 & 24,4 & 14,2 & 10,2 \\
\hline & Concordo pouco & 58 & 16,1 & 10,8 & 5,3 \\
\hline & Concordo muito & 157 & 43,6 & 32,2 & 11,4 \\
\hline
\end{tabular}

Fonte: Elaborado pelos autores. 
Quanto ao preço na assertiva 3 "Me disponho a pagar mais caro por um alimento orgânico", $58,3 \%$ concordam muito com a afirmação, seguido dos que concordaram pouco (29,8\%). Em relação à assertiva 4: "Os alimentos orgânicos são mais saudáveis, pois são livres de agrotóxicos, hormônios e outros produtos químicos", 95,6\% dos entrevistados responderam concordar totalmente. As assertivas 5, 6 e 7 estão relacionadas ao preço entre feiras orgânicas e supermercado, onde na afirmativa 7: "Na feira compro produto orgânico mais barato do que no supermercado" constatou-se que 43,6\% concordam muito com tal afirmação, 24,4\% dos entrevistados não concordam nem discordam da afirmação, 16,1\% dos entrevistados concordam pouco, 9,8\% disseram que discordam muito e por último $6,1 \%$ dos entrevistados discordam pouco da afirmação.

Segundo Patto et al. (2015) as pessoas geralmente têm atitudes relacionadas ao meio ambiente ao sentirem que existe ameaça a si mesmo ou àquilo que valorizam como a saúde ou para manter determinado padrão ou estilo de vida. Estudos realizados na Alemanha relataram que a conscientização ambiental, o bem-estar dos animais e o comércio justo, são as razões mais importantes para determinar o consumo de alimentos orgânicos pelos consumidores (MCEACHERN; MCCLEAN, 2002; TARKIAINEN; SUNDQVIST, 2005; MICHAELIDOU; HASSAN, 2010). Já para outros, aspectos como a preocupação com a saúde, nutrição, segurança alimentar, sabor dos alimentos e alimentos frescos são os principais aspectos que levam ao consumo (CHEN, 2009; HAGHIRI et al., 2009; BRAVO et al., 2013).

Consumidores de alimentos orgânicos percebem estes alimentos como bons para a saúde e para o meio ambiente, uma vez que possuem conhecimento das técnicas e métodos utilizados no cultivo. Entretanto, a decisão de compra do produto orgânico por parte do consumidor está baseada, em primeiro lugar, na saúde e, em um segundo momento, na sustentabilidade (GONÇALVES, 2017). As pessoas consomem tais produtos pela produção orgânica e a sua relação com o meio ambiente e com a saúde da população. O consumidor de alimentos orgânicos é um consumidor diferenciado, já sensibilizado às questões ambientais, de saúde e de alto valor de preço, conforme já apontado por Sousa et al. (2012).

Ao constatar que a maioria dos entrevistados relata estarem dispostos a pagar mais caro por alimento orgânico e que a maioria deles $(43,9 \%)$ reside no bairro 
da Lapa, que segundo o IBGE (2016) e Secretaria Municipal de Saúde (2016) é um bairro que possui renda média de $\mathrm{R} \$ 5.000,00$ por habitante, ou seja, uma população financeiramente diferenciada. De acordo com Sousa et al. (2012), o alimento orgânico não é competitivo ainda no grande mercado geral. Os autores mencionam que o preço do orgânico pode chegar a custar entre 20 e $100 \%$ a mais do que os convencionais, baseado na lei da oferta e da procura.

Azevedo e Pelicioni (2011) apontam efeitos do uso de agrotóxicos na saúde como mal de Parkinson, infertilidade masculina, aborto e alguns tipos de câncer. Outros estudos mencionam o excesso de nitrogênio em várias partes do ecossistema, estes estão relacionados com o uso abusivo de fertilizantes nitrogenados e já possui o limite de segurança ultrapassado (CARVALHO; ZABOT, 2012; GARCIA et al., 2013). Conforme estudos realizados por Rucinski e Brandenburg (2002) em Curitiba (PR), 39,2\% dos entrevistados relataram que agrotóxicos causam danos à saúde e 33,3\% relataram que os agrotóxicos são causadores de câncer nas pessoas. Esta assertiva complementa a primeira assertiva, a qual relacionou produtos orgânicos com benefícios à saúde.

Comparando-se a qualidade dos alimentos orgânicos do supermercado e a qualidade dos produtos orgânicos da feira na assertiva "No supermercado encontro alimentos orgânicos com mais qualidade do que na feira" com 58,1\% que discordam muito da afirmação e $21 \%$ discordam pouco, seguidos por $11,7 \%$ que não concordam nem discordam da afirmação, predominando a melhor qualidade da feira orgânica, do ponto de vista dos consumidores.

Segundo Archanjo et al. (2001) e Gonçalves (2017) frequentadores de feiras orgânicas alegam preferir a feira pelos preços serem mais baixos do que o supermercado, pois não há intermediários, sendo os próprios produtores rurais que realizam a venda diretamente ao consumidor e que os produtos são sempre frescos e de melhor qualidade.

Nas assertivas 3 e 7, "Me disponho a pagar mais caro por alimento orgânico" e "Na feira compro produto orgânico mais barato do que no supermercado", respectivamente, os consumidores apresentam posições diferentes. A decisão do consumidor em pagar mais caro está relacionada às condições financeiras do indivíduo e de sua família. O quanto pagar por um produto orgânico é uma escolha preferencial e 
individualizada para cada alimento orgânico, ou seja, não basta o valor ser permitido no orçamento familiar, depende de quanto está disposto a pagar pelo tipo de alimento orgânico (MARTINS et al., 2006; BARBOSA et al., 2011).

A análise das variáveis no teste ANOVA (One-way) entre os dados de "Como o respondente se desloca até a feira" com as variáveis de grau de concordância foi considerado para o teste o grau de significância menor que 0,05 , destacando-se com grau de significância aceitável conforme Hair et al. (2005). Para as variáveis com grau de significância abaixo de 0,05 como: "Gosto de consumir alimentos orgânicos porque trazem benefícios para a saúde”, quando comparados com os frequentadores que se deslocam a pé versus os que se deslocam de carro até a feira, constatou grau de significância de 0,044 . Essa variável pode estar relacionada com a questão da distância em que o respondente reside ou relação com a idade de cada indivíduo. A distância onde reside e a idade que possui pode ser um limitador e fator de decisão sobre como se deslocar na cidade, já que conforme dados do IBGE (2017) a cidade possui área territorial de $1.521,110 \mathrm{~km}^{2}$ e população estimada em 11.253 .503 habitantes, sendo esses dois fatores influenciadores na decisão de deslocamento do indivíduo.

A existência de diferenças de médias por gênero, faixa etária e escolaridade foram testadas por meio de uma análise de variância (One Way ANOVA), conforme dados dispostos na Tabela 3. Destaca-se na análise das diferenças de escolaridade (comparação de ensino superior ou acima com ensino médio ou abaixo) a variável "Me disponho a pagar mais caro por um produto orgânico", $(\mathrm{p}<0,05)$. Não foram encontradas diferenças significantes para as demais assertivas entre os dois grupos de escolaridade. Nos estudos de Rousseau e Vraken (2013), realizados na Bélgica, que avaliaram os motivos que levam os consumidores a escolherem entre duas variedades de maçã (orgânica e convencional) com diferenças no sabor, preço, forma, origem e apresentação da etiqueta, foi identificado que a idade e sexo das pessoas entrevistadas não afetaram a disposição dos entrevistados em pagar mais caro em um alimento orgânico. Porém, percebeu-se que pessoas com ensino superior estão dispostas a pagar mais caro do que pessoas que possuem grau de escolaridade inferior. 
Tabela 3. p-valores obtidos na análise de variância para verificar a existência (ou não) de diferenças - significativas entre as assertivas testadas e a variável "escolaridade"

Assertivas

p-valor

Gosto de consumir alimentos orgânicos porque trazem benefícios para a saúde. 0,054

Gosto de consumir alimentos orgânicos porque trazem benefícios para o meio ambiente.

Me disponho a pagar mais caro por um produto orgânico. 0,034

Os alimentos orgânicos são mais saudáveis, pois são livres de agrotóxicos, hormônios e outros produtos químicos.

Eu compro alimentos orgânicos no supermercado. 0,717

No supermercado encontro alimentos orgânicos com mais qualidade do que na feira.

Na feira compro produtos mais baratos que no supermercado. 0,86 Fonte: Elaborado pelos autores.

$\mathrm{Na}$ análise por gênero (Tabela 4), as assertivas "Gosto de consumir alimentos orgânicos porque trazem benefícios para a saúde" e "Gosto de consumir alimentos orgânicos porque trazem benefícios para o meio ambiente" foram as únicas que apresentaram diferença significante $(\mathrm{p}<0,05)$, o que indica a preocupação dos consumidores de produtos orgânicos com a saúde e meio ambiente. Estudos revelam que a preocupação do consumidor com a saúde é o motivo mais comum para escolher os alimentos orgânicos (CHEN, 2009).

Conforme a Tabela 2, 95,8\% dos entrevistados (Concordam muito) com a afirmação "Gosto de consumir alimentos orgânicos porque trazem benefícios para a saúde". Segundo Neves et al. (2014) os consumidores de produtos orgânicos, mesmo não possuindo vasto conhecimento sobre agricultura orgânica, possuem consciência para entender que o consumo de alimentos orgânicos ameniza problemas relacionados com a saúde. Também Bravo et al. (2013) e Patto et al. (2015) relatam que os consumidores de alimentos orgânicos consomem por motivos relacionados com a saúde e meio ambiente (CHEN, 2009). Os vários problemas alimentares decorrentes de doenças, contaminações por agrotóxicos, uso de hormônios e antibióticos na alimentação dos animais fizeram com que os consumidores se tornassem mais preocupados e conscientes com a qualidade dos alimentos e com a saúde, sendo mais criteriosos na compra de alimentos. 
Com a afirmação "Gosto de consumir alimentos orgânicos porque trazem benefícios para o meio ambiente" 90,5\% disseram concordar muito com a afirmação. Estudos fornecem evidências de que a preocupação ambiental é um dos principais determinantes da compra de alimentos orgânicos (CHEN, 2009).

Tabela 4. p-valores obtidos na análise de variância para verificar a existência (ou não) de diferenças significativas entre as assertivas testadas e a variável "gênero"

\begin{tabular}{lc}
\hline \multicolumn{1}{c}{ Variável } & Significância \\
\hline $\begin{array}{l}\text { Gosto de consumir alimentos orgânicos porque trazem benefícios para a saúde. } \\
\begin{array}{l}\text { Gosto de consumir alimentos orgânicos porque trazem benefícios para o meio } \\
\text { ambiente. }\end{array}\end{array}$ & $0,000^{*}$ \\
\hline $\begin{array}{l}\text { Me disponho a pagar mais caro por um produto orgânico. } \\
\text { Os alimentos orgânicos são mais saudáveis, pois são livres de agrotóxicos, hormô- }\end{array}$ & 0,103 \\
nios e outros produtos químicos. & 0,379 \\
\hline Eu compro alimentos orgânicos no supermercado. & 0,43 \\
$\begin{array}{l}\text { No supermercado encontro alimentos orgânicos com mais qualidade do que na } \\
\text { feira. }\end{array}$ & 0,359 \\
\hline Na feira compro produtos mais baratos que no supermercado. & 0,188 \\
\hline
\end{tabular}

* Significativa ao nível de 0,05 .

O consumidor ao realizar uma compra deve passar antes por um processo que envolve influências sociais, de marketing e situacional, visto que o consumidor realiza um processo de reconhecer a necessidade da compra, a busca por informação, avalia se existe alternativa, toma a decisão em comprar e faz a avaliação da compra após o consumo (CHURCHILL et al., 2010).

\section{CONCLUSÃO}

A pesquisa permitiu identificar que os entrevistados (em sua maioria mulheres), com faixa etária entre 30 e 60 anos e ensino superior completo como potenciais consumidores de produtos de feira orgânica. Além disso, a maioria dos consumidores adquire os produtos orgânicos há mais de 4 anos, frequentando as feiras semanalmente e apontam a saúde como fator decisivo para a escolha. Os consumidores 
de alimentos orgânicos entrevistados compram tais produtos porque a maioria acredita que sejam mais seguros e mais nutritivos, devido à ausência de substâncias nocivas, como agrotóxicos. De acordo com os respondentes esses alimentos possuem qualidade superior aos produtos convencionais, possuem sabor mais agradável e maior durabilidade. Dessa forma, se dispõem a pagar mais caro pelos benefícios do alimento orgânico, tanto para saúde quanto para o meio ambiente.

Os consumidores têm preferência por feiras, quando comparados aos alimentos oferecidos nos supermercados, tanto por conta da qualidade quanto do preço. $\mathrm{O}$ mercado de orgânicos também está atrelado à produção sustentável e de forma a não agredir o meio ambiente e compreender a percepção de consumidores contribui também para novas estratégias de popularização do consumo de orgânicos, com foco no marketing verde, em toda a cadeia de produção de alimentos orgânicos.

O processo contínuo de educação para o consumo consciente de uma maior parcela da população é possível nas feiras de produtos orgânicos, visto que alguns dos produtores fazem a venda direta ao consumidor, possibilitando a explicação sobre como a produção de um alimento orgânico é também sustentável e saudável ao mesmo tempo.

\section{REFERÊNCIAS}

ABREU, L. S.; KLEDAL, P.; PETTAN, K.; RABELLO, F.; MENDES, S. C. Trajetória e situação atual da agricultura de base ecológica no Brasil e no estado de São Paulo. Cadernos de Ciência \& Tecnologia, v. 26, n. 1, p. 149-178, 2009.

ALBUQUERQUE, N. V.; SILVA, D. S. P.; PADOVAN, M. P. Perfil dos Consumidores e Comercialização de Produtos Orgânicos em Campo Grande, Mato Grosso do Sul. Cadernos de Agroecologia, v. 9, n. 4, 2015.

ALVES, A. C. O.; SANTOS, A. L. S.; AZEVEDO, R. M. M. C. Agricultura orgânica no Brasil: sua trajetória para a certificação compulsória. Revista Brasileira de Agroecologia, v. 7, n. 2, p. 19-27, 2012. 
ARCHANJO, L. R.; BRITO, K. F. W.; SAUERBECK, S. Alimentos orgânicos em Curitiba: consumo e significado. Cadernos de Debate, v. 8, p. 1-6, 2001.

AZEVEDO, E.; PELICIONI, M. C. F. Promoção da Saúde, Sustentabilidade e Agroecologia: uma discussão intersetorial. Saúde e Sociedade, v. 20, n. 3, p. 715-729, 2011.

BARBOSA, S. C.; MATTEUCCI, M. B. A.; LEANDRO, W. M. et al. Perfil do consumidor e oscilações de preços de produtos agroecológicos. Pesquisa Agropecuária Tropical, v. 41, n. 4, 2011.

BRASIL. Lei $\mathrm{n}^{\circ} 10.831$, de 23 de dezembro de 2003. Dispõe sobre a agricultura orgânica e dá outras providências. Disponível em: http://www. planalto. gov. br/ ccivil_03/leis/2003/110. Acesso em: 24 abr. 2018.

BRASIL. Decreto $n^{0}$ 6.323, de 27 de dezembro de 2007. Regulamenta a Lei $n^{-}$ 10.831, de 23 de dezembro de 2003, que dispõe sobre a agricultura orgânica, e dá outras providências. Disponível em: http://www.planalto.gov.br/ccivil_03/_ ato2007-2010/2007/Decreto/D6323.htm. Acesso em: 24 abr. 2018.

BRAVO, C. P.; CORDTS, A.; SCHULZE, B.; SPILLER, A. Assessing determinants of organic food consumption using data from the German National Nutrition Survey II. Food Quality and Preference, v. 28, n. 1, p. 60-70, 2013.

CAMPANHOLA, C.; VALARINI, P. J. A agricultura orgânica e seu potencial para o pequeno agricultor. Cadernos de Ciência \& Tecnologia, v. 18, n. 3, p. 69-101, 2001.

CARVALHO, N. L.; ZABOT, V. NITROGÊNIO: NUTRIENTE OU POLUENTE?. Electronic Journal of Management, Education and Environmental Technology (REGET), v. 6, n. 6, p. 960-974, 2012.

CASEMIRO, A. D.; TREVIZAN, S. P. Alimentos Orgânicos: Desafios para o Domínio Público de um conceito. In: 2nd International Workshop, Advances in Cleaner Production. São Paulo: Brazil. 2009.

CHEN, M. Attitude toward organic foods among Taiwanese as related to health consciousness, environmental attitudes, and the mediating effects of a healthy lifestyle. 
British Food Journal, v. 111, n. 2, p. 165-178, 2009.

GILBERT, A.; PETER, J. P.; CHURCHILL JR. Marketing: criando valor para os clientes. São Paulo: Saraiva, 2010.

DIAS, C. B. R.; FREITAS, H. R.; SILVA, T. R. F. C.; GALHARDO, C. X.; CARVALHO NETO, M. F. Promoção da Agroecologia e Segurança Alimentar junto a Escola do Núcleo Habitacional 2 do Perímetro Irrigado Nilo Coelho, Petrolina-PE. Cadernos de Agroecologia, v. 10, n. 3, 2016.

DHIVYA, J.; RANGASWAMY, S. Consumers Preference Towards the Purchase of Organic farm Products. International Journal of Scientific Research, v. 5, n. 8, 2016.

FRANÇA, J. U. B.; LAMANO-FERREIRA, A. P. N.; RUIZ, M. S. et al. Ecological knowledge about protected areas in the East Zone of São Paulo, SP: implications for sustainability in urban area. Holos, v. 3, p. 174-185, 2016.

GARCIA, G.; CARDOSO, A. A.; SANTOS, O. A. M. Da escassez ao estresse do planeta: um século de mudanças no ciclo do nitrogênio. Química Nova, p. 1468-1476, 2013.

GONÇALVES, K. S. Percepção e comportamento ambiental de consumidores de produtos orgânicos das feiras do Parque Água Branca. Dissertação (Mestrado Profissional em Administração) - Pós-Graduação em Gestão Ambiental e Sustentabilidade - GeAS, Universidade Nove de Julho, 2017. 84p.

GONZAGA, C. A. M. Marketing verde de produtos florestais: teoria e prática. Floresta, v. 35, n. 2, p. 353-368.

HAGHIRIA, M.; HOBBS, J. E.; MCNAMARA, M. L. Assessing consumer preferences for organically grown fresh fruit and vegetables in Eastern New Brunswick. International Food and Agribusiness Management Review, v. 12, n. 4, p. 81, 2009.

HARARI, Y. N. Sapiens: uma breve história da humanidade. L\&PM, 2015. GONÇALVES, K. S.; LAMANO-FERREIRA, A. P. N.; MOREIRAS, A. A.; AQUINO, S. Agricultura orgânica: saúde, meio ambiente e sustentabilidade. In: AMÉRICO-PINHEIRO, J. H. P.; BENINI, E. M.; SILVA, A. L. C. Meio Ambiente: Gestão e Sustenta- 
bilidade, p. 240. Tupã: ANAP, 2017.

LEE, A. C. K.; MAHESWARAN, R. The health benefits of urban green spaces: a review of the evidence. Journal of Public Health, v. 33, n. 2, p. 212-222, 2011.

SAMBIASE, L. M.; GIRO, M. R.; SATIKO, S. G. Um estudo exploratório dos fatores relevantes na decisão de compra de produtos orgânicos. RAM. Revista de Administração Mackenzie, v. 5, n. 1, 2004.

LOPES, V. N.; PACAGNAN, M. N. Marketing verde e práticas socioambientais nas indústrias do Paraná. Revista de Administração, v. 49, n. 1, p. 116-128, 2014.

MARTINS, V. A.; CAMARGO FILHO, W. P.; BUENO, C. R. F. Preços de frutas e hortaliças da agricultura orgânica no mercado varejista da cidade de São Paulo. Informações Econômicas, v. 36, n. 9, p. 42-52, 2006.

MCEACHERN, M. G.; MCCLEAN, P. Organic purchasing motivations and attitudes: are they ethical?. International Journal of Consumer Studies, v. 26, n. 2, p. 85 92, 2002.

MICHAELIDOU, N.; HASSAN, L. M. Modeling the factors affecting rural consumers' purchase of organic and free-range produce: A case study of consumers' from the Island of Arran in Scotland, UK. Food Policy, v. 35, n. 2, p. 130-139, 2010.

MINISTÉRIO DA AGRICULTURA PECUÁRIA E ABASTECIMENTO (MAPA). (2015). Número de produtores orgânicos cresce 51,7\% em um ano. Disponível em: http:// www.agricultura.gov.br/comunicacao/noticias/2015/03/numero-de-produtores-organicos-cresce-51porcento-em-um-ano. Acesso em: 13 mar. 2017.

MINISTÉRIO DA SAÚDE (2014). Guia alimentar para a população brasileira. 2. ed. Brasilia. Disponível em: http://bvsms.saude.gov.br/bvs/publicacoes/guia_alimentar_populacao_brasileira_2ed.pdf. Acesso em: 12 abr. 2017.

NANDI, R.; BOKELMANN, W.; GOWDRU, N. V.; DIAS, G. Consumer motives and purchase preferences for organic food products: Empirical evidence from a consumer survey in Bangalore, South India. Journal of International Food \& Agribusiness Marketing, v. 28, n. 1, p. 74-99, 2016. 
NEVES, G. Y. S.; STRÖHER, G. L.; SILVA, A. A.; BENTO, J. D.; CAMARGO, L. P. Consumo e percepção dos atributos dos alimentos orgânicos por parte dos consumidores. Revista Diálogos \& Saberes, v. 9, n. 1, 2014.

PATTO, A. A.; PATTO, A. R.; MOURA, A. C.; MARTINS, J. F. Impacto da consciência ambiental e da atitude na intenção de compras de produtos orgânicos. Ciências Sociais em Perspectiva, v. 14, n. 26, p. 01-29, 2014.

PAULUS, G.; MULLER, A. M.; BARCELLOS, L. A. R. Agroecologia aplicada: práticas e métodos para uma agricultura de base ecológica. Porto Alegre: EMATER/RS, 2000. p. 86.

PENTEADO, S. R. Introdução à agricultura orgânica. Aprenda Fácil, 2003.

PLANETA ORGÂNICO. Posição do Brasil no mercado de alimentos orgânicos, 2015. Disponível em: http://planetaorganico.com.br/site/index.php/c/mercado/. Acesso em: 12 abr. 2017.

PONISIO, L. C.; KREMEN, C. System-level approach needed to evaluate the transition to more sustainable agriculture. In: Proc. R. Soc. B. The Royal Society, 2016. p. 2015-2913.

RAVELLI, W. M.; MORAES, D. O.; LIMA-FILHO, D. O. Estilo de vida dos consumidores de alimentos orgânicos em Campo Grande-MS: uma segmentação psicográfica com aplicação do modelo VALS-2. REA-Revista Eletrônica de Administração, v. 12, n. 2, p. 142-156, 2013.

ROUSSEAU, S.; VRANKEN, L. Green market expansion by reducing information asymmetries: Evidence for labeled organic food products. Food Policy, v. 40, p. 31-43, 2013.

SANTOS, J. O.; SANTOS, R. M. S.; BORGES, M. G. B. et al. A evolução da agricultura orgânica. Revista Brasileira de Gestão Ambiental, v. 6, n. 1, p. 35-41, 2013.

SILVA, J. M.; NOVATO-SILVA, E.; FARIA, H. P.; PINHEIRO, T. M. M. Agrotóxico e trabalho: uma combinação perigosa para a saúde do trabalhador rural. Ciência \& Saúde Coletiva, v. 10, n. 4, p. 891-903, 2005. 
SOUSA, A. A.; AZEVEDO, E.; LIMA, E. E.; SILVA, A. P. F. Alimentos orgânicos e saúde humana: estudo sobre as controvérsias, 2012. Disponível em: https://www.scielosp. org/article/rpsp/2012.v31n6/513-517/. Acesso em: 23 abr. 2018.

TARKIAINEN, A.; SUNDQVIST, S. Subjective norms, attitudes and intentions of Finnish consumers in buying organic food. British Food Journal, v. 107, n. 11, p. 808-822, 2005.

TILIO NETO, P. Ecopolítica das mudanças climáticas: o IPCC e o ecologismo dos pobres. Rio de Janeiro: Centro Edelstein de Pesquisas Sociais, 2010. Disponível em: http://books.scielo.org. Acesso em: 25 abr. 2018.

VILCKAS, M.; DINIZ, N.; FLÁVIO, J. Agregação de valor: uma alternativa para a expansão do mercado de alimentos orgânicos. Organizações Rurais \& Agroindustriais, v. 9, n. 1, 2007.

Recebido em: 26/06/2017

Aceito em: 20/07/2018 